\title{
DA SEGUNDA MÃO À SEGUNDA CHANCE: LUXO E SUSTENTABILIDADE EM BRECHÓS DE PARIS E SÃO PAULO
}

\author{
From secondhand to second chance: luxury and \\ sustainability in thrift shops from Paris and São Paulo \\ Desde la segunda mano hasta la segunda oportunidad: \\ lujo y sustentabilidad en mercadillos de Paris y São Paulo
}

\author{
Cecília Elisabeth Barbosa Soares \\ Universidade Federal do Rio de Janeiro, Rio de Janeiro, Brasil. \\ Doutora em Sociologia pelo Instituto de Estudos Sociais e Políticos da Universidade do Estado do Rio de \\ Janeiro (Uerj). Mestre em Sociologia e Antropologia pela Universidade Federal do Rio de Janeiro (UFRJ). \\ E-mail: ceciliaebsoares@gmail.com
}

\begin{abstract}
RESUMO A indústria têxtil tem-se conscientizado cada vez mais dos impactos ambientais ligados à produção de roupas, e há uma pressão constante para reduzir resíduos e revisar preferências e princípios dos consumidores. A compra de peças de segunda mão deixou de ser um lugar marginal, associado à suposta incapacidade da clientela de "comprar novo", e negócios no setor passaram a ser vistos como estratégicos. Este artigo explora diferentes propósitos de brechós como negócio a partir de entrevistas em profundidade com três empresárias das cidades de Paris e São Paulo, focando em suas visões sobre mudanças, novas chances, sustentabilidade e propósitos modernos para negócios.
\end{abstract}

PALAVRAS-CHAVE Brechó, Sustentabilidade, Reuso.
ABSTRACT The fashion industry has been growing increasingly aware of the environmental impacts caused by clothing production and the pressure to reduce waste and review consumers' preferences and principles has been constant. Second-hand consumption has changed from a marginal practice, linked to the supposed incapacity of the client of "buying new", and businesses in the sector became strategic. This article explores the different purposes of thrift shops as businesses with three in-depth interviews with businesswomen in the cities of Paris and São Paulo, focusing on their visions on changes, new chances, sustainability, and modern purposes for businesses.

KEYWORDS Thrift shop, Sustainability, Reuse.

RESUMEN La toma de conciencia de los impactos en el medioambiente provocados por la produción de ropa es crecente en la industria textil; y los agentes de esta son presionados para que se reduzcan los residuos y que los consumidores elijan según preferencias y principios de vida. Las tiendas de segunda mano ya no son una práctica marginal, asociada a una incapacidad de "comprar algo nuevo", los negocios en el sector pasaron a considerarse opciones estratégicas. Este artículo explora diferentes propósitos de la venta de segunda mano desde entrevistas en profundidad realizadas con tres empresarias de las ciudades de Paris y São Paulo, enfocándose en sus perspectivas sobre cambios, nuevas oportunidades, sustentabilidad y propósitos modernos de los negocios.

PALABRAS-CLAVE Mercadillo, Sustentabilidad, Reuso. 


\section{INTRODUÇÃo}

Nos últimos dez anos, as questões ambientais estiveram em pauta na mídia e no meio acadêmico, além de terem sido incluídas em diversas discussões, inclusive relacionadas à produção e ao consumo. Por outro lado, a indústria têxtil é fonte notória de poluição, associada a uma cadeia muito complexa. Apesar de ambos os pontos já não serem recentes, a principal relação de consumo com peças de indumentária e acessórios ainda consiste na "busca por roupa nova" segundo a moda vigente.

De fato, a moda, tal como desenvolvida sobretudo do século XIX em diante, se pautou no princípio de "coleção", procurando cristalizar, em meio a suas criações, um espírito de cada época, assim como insights daqueles que viriam a ser designados "estilistas" (GRUMBACH, 1993). As coleções, por excelência, acompanham as estações do ano; ademais, é comum que marcas escolham temáticas sobre as quais se debruçam para desenvolver suas referências. Diante dessas especificidades, as coleções se tornam rapidamente datáveis, e mesmo datadas, ou seja, defasadas em relação a aspirações, gostos e leituras de mundo posteriores. Esta especificidade da moda em relação ao tempo leva, inclusive, o escritor Anatole France (1921 apud SILVA, 2005, p. 31) a considerar que se lhe fosse

dado escolher no amontoado dos livros que serão publicados cem anos após a minha morte, [...] escolheria tranquilamente [...] uma revista de moda para ver como as mulheres estarão vestidas um século após meu falecimento. E estes pedacinhos me diriam mais sobre a humanidade futura do que todos os filósofos, romancistas, pregadores e sábios.

Os duzentos anos de produção e descarte das peças de moda parecem estranhamente destoantes das preocupações em relação ao ambiente (GWOZDZ; STEELEN NIELSEN; MÜLLER, 2017) e ao impacto ambiental da indústria têxil. A biografia de praxe das roupas (KOPYTOFF, 1988) assumia que cada peça seria detida por uma única proprietária para ser, em seguida, descartada e se dirigir a um paradeiro desconhecido. O Gráfico 1 apresenta o forte crescimento nas vendas de peças de roupa entre 2000 e 2015 e a tendência decrescente no total de vezes em que cada item é usado. Assim, os armários tendem a se rechear, sem que se substitua peças desgastadas por novas, mas compondo um acervo mais pautado na volátil categoria do gosto e da identificação pessoal com cada bem.

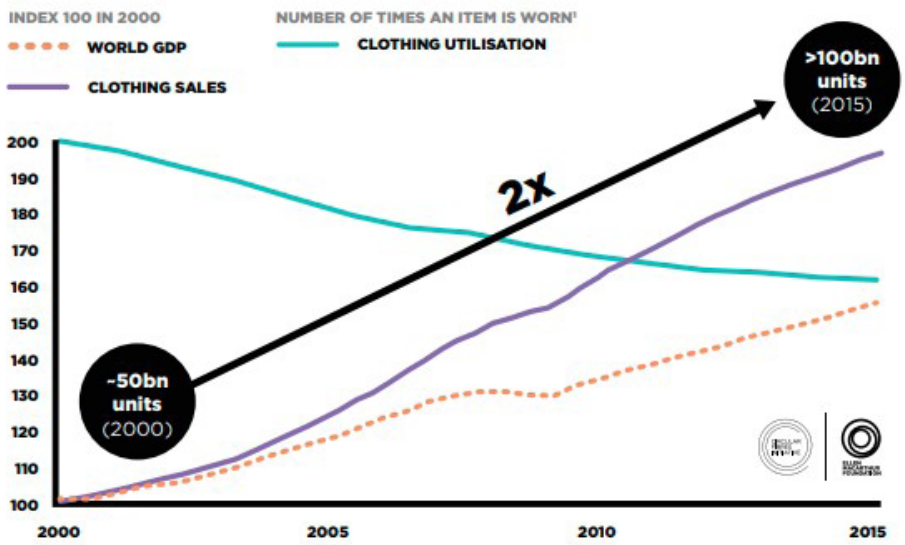

Gráfico 1. Crescimento das vendas de roupas e declínio no uso de cada peça entre 2000 e 2015. Fonte: Ellen MacArthur Foundation (2017, p. 18). 
Contudo, observa-se um crescimento significativo do comércio de peças de segunda mão no mundo, impulsionado, em parte, pelo estabelecimento da internet como canal de compra e venda. Em algumas localidades, o consumo em brechós já dispunha de uma tradição, como no caso do Exército de Salvação estadunidense ou na prática de salaula, no Zâmbia (HANSEN, 2000). As especificidades não são apenas geográficas, mas também dizem respeito aos tipos de peças escolhidos e à relação entre vendedoras e compradoras.

Nesse contexto, este artigo aborda as motivações de fundadoras de brechós com peças de luxo em duas cidades, Paris e São Paulo, através de entrevistas em profundidade e uma contextualização etnográfica das relações locais com peças de segunda mão (BORGES; DUBEUX, 2012; KRÜGER, 2010). A partir das narrativas, estabeleceu-se semelhanças e diferenças entre as motivações sobre os negócios e as relações com peças e perspectivas sobre o impacto do comércio no contexto global. Este material foi coletado durante o ano de 2018, e em seguida transcrito, traduzido e editado pela autora. Para preservar a identidade de cada entrevistada, atribuiu-se pseudônimos.

\section{CONTEXTOS DE BRECHÓS EM PARIS E SÃO PAULO}

Paris se consolidou como referência para a moda internacional, nos moldes modernos, do século XIX em diante (HAZAN, 2017). Mesmo antes, contudo, já irradiava uma centralidade em termos de gosto e elegância, entre outros, por conta da sólida estrutura do Antigo Regime (ROCHE, 1989), em que indumentária e hierarquias estamentais colaboravam para a perpetuação de um complexo sistema de moda (BARTHES, 2014). Se, por um lado, a Cidade Luz é pródiga em modelos e referências de estilo, por outro, é conhecida pelo alto custo do metro quadrado, pelas instalações exíguas e pela alta rotatividade das coleções disponíveis no varejo geral.

Em meio a este conjunto, a cidade oferece uma considerável variedade de canais de segunda mão (Figuras 1 e 2)- desde os famosos marché aux puces, onde se pode encontrar um pouco de tudo, ao sabor do acaso, até sequências de brechós voltadas para uma das especialidades da cidade: a tradição e as marcas locais. Para além das lojas físicas, o e-commerce tem se tornado uma modalidade de venda consolidada na Europa como um todo.

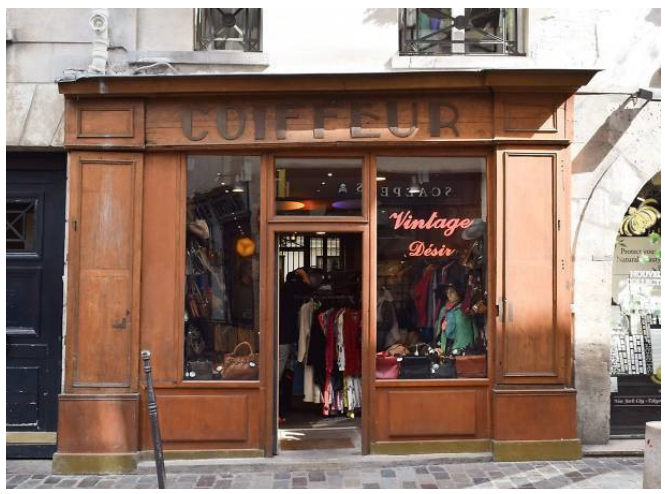

Figura 1. Fachada de brechó parisiense ${ }^{1}$ do $4^{\circ}$ arrondissement, altura da rue des Rosiers Fonte: Time Out.

1. Para mais informações consulte: https://www.timeout.com/paris/en/shopping/vintagedesir. Acesso em: 11 nov. 2020. 


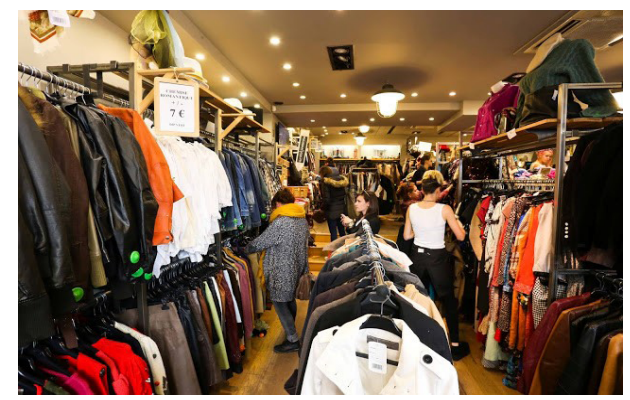

Figura 2. Exemplo de interior de brechó "generalista" em Paris². Fonte: Obsession de Style.

Em contrapartida, a compra em brechós foi relegada, até fins do século XX, no Brasil, como prática secundária diante da franca preferência por peças novas, sobretudo com uma consolidação do modelo dos shopping centers a partir da década de 1980 (FERREIRA FREITAS, 1996). Até mesmo a exploração etimológica do termo "brechó", associada a um mito de origem de "loja de Belchior", remete a uma antiga revenda de secos e molhados cujo dono assim se nomeava. No conto "Ideias do Canário", de Machado de Assis, lê-se: "Escapei saltando para dentro de uma loja de belchior... A loja era escura, atulhada das cousas velhas, tortas, rotas, enxovalhadas, enferrujadas que de ordinário se acham em tais casas, tudo naquela meia desordem própria do negócio” (1997, p. 66).

O aspecto da loja é compatível com o estado dos bens que vende: desorganizada, na penumbra, e tão pouco acolhedora quanto a ideia de compra de um produto de uso já avançado. Na polarização de categorias, o "novo" não apenas se opõe ao "antigo", como também a "sem uso", o uso trazendo também a tiracolo um forte elemento de poluição (DOUGLAS, 2012). Nada mais distante, em princípio, do mundo do luxo. A compra em brechós tem, porém, expressado significados variados. A partir disso, motivações e visões de mundo são ricos testemunhos sobre a cultura material, os novos tempos e mesmo o que se configura como "negócio oportuno", e por isso optou-se por entrevistas em profundidade com três empresárias: duas baseadas em Paris e uma em São Paulo.

\section{AS MOTIVAÇÕES DAS PROPRIETÁRIAS}

As três entrevistadas contaram sua trajetória e perspectivas nas sedes de seus empreendimentos. Elas optaram pelo mundo da segunda mão através de caminhos particulares e vivências ricas.

A Tabela 1 sintetiza algumas características das entrevistadas.

Tabela 1. Características das entrevistadas.

\begin{tabular}{llllll}
\hline NOME & IDADE & $\begin{array}{c}\text { FORMAÇÃO } \\
\text { ACADÊMICA }\end{array}$ & $\begin{array}{c}\text { FORMATO DO } \\
\text { NEGÓCIO }\end{array}$ & ABRANGÊNCIA & PRINCIPAL FOCO \\
\hline Inès & 35 & Moda & Online & Luxo & Sustentabilidade \\
\hline Stella & 35 & Comunicação & Físico & Luxo & $\begin{array}{l}\text { Estética e } \\
\text { democratização }\end{array}$ \\
\hline $\begin{array}{l}\text { Maria } \\
\text { Clara }\end{array}$ & 35 & Publicidade & Online & $\begin{array}{l}\text { Generalista com } \\
\text { peças de luxo }\end{array}$ & $\begin{array}{l}\text { Novas frentes } \\
\text { de negócio }\end{array}$ \\
\hline
\end{tabular}

2. Para mais informações, consulte: http://www.obsessiondestyle.com/2013/04/brechos-deparis.html. Acesso em: $11 \mathrm{dez} .2020$. 


\section{Inès: o brechó como causa}

À época da entrevista, Inès vivia em Paris há 14 anos, dez deles trabalhando diretamente com moda:

Trabalhei em várias maisons de alta costura ...e me dei conta do impacto enorme da fabricação dos produtos [...] Química pesada, muito poluente e que a gente ainda não sabe muito bem tratar, hoje. ...As matérias-primas ...pedem inseticida, [...] culturas sedentas em água. [...] Ainda por cima, compramos imensamente. É um desperdício, poderíamos reciclar etc. A segunda parte são os estoques. As empresas têm estoque. As pessoas têm estoque nos armários etc. Então, pensei: "hoje, chegamos num ponto em que não é mais necessário fabricar. Já tem mercadoria o suficiente no planeta”.

Após dez anos de experiência direta com o mundo da moda e da alta costura, Inès sentiu um "déclic" em função do alto volume de peças e da questão ambiental atrelada à produção:

Tem uma espécie de onda do preço, uma tomada de consciência geral do impacto da indústria têxtil sobre o nosso ambiente [...] Isso deixa as vendas mais lentas, de modo geral, mas ainda assim são consideráveis. [...] As coleções são muito legais aqui em Paris. A meu ver, ainda é a capital da moda. Muitos estrangeiros vêm pra cá pra comprar.

Para ela, o formato do brechó traria um respeito às peças, que deveriam ser valorizadas, e para as quais um "fim de vida” chegava rápido demais:

Pensei: "vou montar um blog pra vender essas peças, valorizando, tirando boas fotos e com boas descrições” [...] Nem sempre foi super formal..., estou em EURL ${ }^{3}$ há um ano. [...] Temos uma bela clientela.... Digamos que 50\% querem comprar moda mais barato. E 50\% com preocupação ambiental, que diz "cansei de comprar roupa de má qualidade. Cansei de financiar essa indústria [...] Quero mudar minha maneira de consumir, ser protagonista da minha vida". E é legal oferecer às pessoas que elas comprem entendendo o que tem por trás.[...] Para não deixar passar a esperança e o simbólico do que tem por trás. [...] 0 meu objetivo é esvaziar o armário das pessoas. Muitos clientes, [...] estrangeiros, entre 30 e 50\% [...] É tocar um pouquinho de cada um, através das palavras-chave bem trabalhadas.

O impacto da poluição do processo produtivo levou Inès a concluir que a principal tarefa comercial consistiria em conserto e redistribuição de peças em excelente estado. Em termos pessoais, ela reforça sua atuação por convicção, mais do que em função de um retorno finaneiro:

É casa de ferreiro, espeto de pau: compro muito pouca roupa [...]. Tem outras prioridades na vida. [...] Não preciso de muito dinheiro pra viver. De quebra, faço pelo prazer. [...] É uma história bem corajosa. Tem que ter muita convicção. É isso que me leva. [...] Adoro surfar e aproveitar essas belezas naturais. [...] Fico doente [...] com o que estamos fazendo com o planeta.

3. Entreprise Unipersonnelle à Responsabilité Limitée é uma modalidade francesa de empresa de pequeno porte. 
Paradoxalmente, o consumidor final assistiria a um barateamento da moda como um todo, sem conseguir identificar o real preço pago em termos de comprometimento ambiental, em especial nas etapas da cadeia produtiva realizadas fora da Europa Ocidental. Ela alerta que "pra que os artigos saiam a esse preço, não dá pra se iludir, é que tem alguém prejudicado na escolha e são sempre os mesmos. Os países em desenvolvimento. [...] A mão de obra infantil. É puro delírio [...]”. Diante dessas considerações, Inès se motiva sobretudo em prol do que considera "peças duráveis", ou seja, dotadas de uma matéria-prima que sofreu processos bem trabalhados: “até em campo arqueológico já encontraram peças de couro [...] Eu tenho peças com mais de 20 anos e que não mudaram uma vírgula”.

A qualidade e a durabilidade são, portanto, para Inès, as principais características de um produto, mais do que marcas estabelecidas. Embora a reputação das empresas possa trazer bons referenciais, nem sempre essa postura seria fidedigna:

Algumas marcas são engajadas e dá pra confiar [...] Dito isso, várias surfam na tendência e falam mais do que fazem. [...] Então tem que verificar os bastidores [...] Desconfio mais é das marcas menores [...] que dizem fabricar com critério [...] É muito caro produzir assim e [...] aí, quando percebem que deram um passo maior que a perna, acabam transigindo sobre algumas coisas e no final essa imagem ambiental não é tão certa [...] Não dá mais pra aceitar que uma marca com [...] reputação não siga [...] critério algum.

A partir dessa visão, Inès seleciona e avalia cada item:

O critério é a qualidade do produto. A atemporalidade do estilo [...] E o made in, se for feito na China já não me interessa [...] porque financia a indústria [...] A marca é secundária, eu olho o corte do produto, o caimento. Primeira coisa que faço é experimentar. [...] Depois de 8 meses, a pessoa tem o direito de reaver o produto [...] Mas já me aconteceu, se o item tiver me dado muito trabalho, de comprar [...] pra não perder o esforço [...] Eu limpo, eu retoco [...], faço pesquisa na internet pra reaver o preço original, eventuais fotos de famosas com a peça. [...] Em seguida tem as descrições em inglês, em francês e a recepção de clientes, só pra começar [...] 0 trabalho sobre uma peça pode ir de 2 horas a 2 dias.

\section{Por que o tempo mínimo de consignação são 8 meses?}

Porque cobre duas coleções e permite de encontrar clientes para os produtos [...] É o tempo de valorizar bem [...]. E uma coisa legal é que nesse meio-tempo as coisas às vezes mudam. 0 que não era tendência, [...] Por exemplo, [...] esses óculos aqui. Há 5 anos era invendável. [...] Mas aí [...] uma ou duas meninas [...] decidiram resgatar esse estilo pra ordem do dia [...], voltou e voltou com força.

Com este estudo, a precificação leva em consideração uma sequência de critérios:

Eu fixo o preço em função do [...] retail [...] e do preço psicológico [...] que estamos dispostos a pagar para comprar de segunda mão, ou seja, além de 50\% não vende. [...] Por exemplo, um vestido Chloé de 
2000 euros, aqui sai no máximo a 500. [...] Via de regra tento manter esse patamar de $50 \%$ do preço de loja, a menos que sejam peças raras. Algumas são muito procuradas [...], tenho clientes que compram muito e pedem itens de coleção. É bem frequente, sobretudo clientes afortunadas ou então umas minas que trabalham com moda e compram na venda interna das marcas. [...] Aí elas compram peças que quase dá pra encontrar ainda em loja [...]. (Inès)

Em meio a sua atuação solo, Inès lidava com altos gastos. Embora considerasse a clientela boa, o projeto ainda não tinha se tornado plenamente rentável. De fato, a venda internacional trazia desafios, como os impostos a mais, que Inès considerava abusivos: "é enorme, e mais, é ridículo. Acho inadmissível [...], a gente tenta lutar contra o desperdício, a poluição". Finalmente, a concorrência online tendia a desvalorizar os produtos que eram vendidos mais baratos e com um controle de qualidade menor. Para Inès, o bom tratamento da peça remetia praticamente ao resgate da condição de nova: "eu proponho um produto [...] impecável. Ou seja, a pessoa que receber vai ter a impressão de ter comprado novo".

A sede funcionava como local de encontro e prova de roupas para cientes ocasionais, que concluíam a venda online. Apesar da relação relativamente conflituosa com a cidade, Inès considerava a região do $10^{\circ}$ arrondissement altamente estratégica para o negócio:

Já tem um tempinho que o Marais emburguesou [...] A gente fica meio surtada com o preço, mas na verdade o bairro é do lado do canal Saint-Martin, não muito longe das Buttes-Chaumont. Muito central. E a République é um hub de metrô, o que é ótimo. É a um pulo da gare du Nord. Pra clientela estrangeira, é top [...].

Na perspectiva de Inès, prevalecia uma visão global tanto do processo produtivo e comercial de peças de vestuário como da cadeia logística à qual os bens estão atrelados. Seu trabalho procurava gerar uma segunda chance não só para as roupas, mas para o próprio planeta, agindo em todos os elos que estivessem a seu alcance - desde a própria peça até o papel da embalagem. Esse alto critério tornava algumas decisões custosas, mas o entusiasmo de Inès validava seu engajamento, que ela esperava levar para diferentes locais do mundo. Tinha considerado até mesmo empreender no Brasil, mas mudou de ideia. Considerava que, embora Rio de Janeiro e São Paulo fossem cidades desenvolvidas, as características gerais do país ainda tornavam mais interessante que pessoas viajassem para adquirir peças ou que comprassem diretamente online.

\section{Maria Clara e as vivências brasileiras}

A carioca Maria Clara se mudou para São Paulo ainda jovem, por motivos de trabalho. Atuou em uma sequência de empresas até abrir a sua própria. À época, embora considerasse que "brechó em São Paulo também é uma cultura", identificava mais um "comportamento [...] de pessoas que levam ao brechó e pessoas que vão para o brechó”. Primavam, na cidade,

Casas mais vintage ou super categorizadas, um brechó bem arrumadinho, [...] não tem um brechó bem pulguento, Exército de Salvação [...] O que eu via era [que] o espaço era finito, [...] e a única saída para roupas em especial era em brechó. (Maria Clara) 
Embora a própria Maria Clara frequentasse pouco os brechós antes de lançar o seu negócio, observava padrões de família que considerou marcantes para sua formação:

Essa coisa de olhar para as coisas [...] e ver o valor já existe na família. [...] Não sou uma pessoa que compra muito, mas aquilo, ao longo do tempo, seja uma blusinha, aí depois um sapato, [...] o espaço é o mesmo, aquilo tava uma zona! [...] Sabe quando você bota a roupa e não adianta nem passar. [...] Era a minha referência. Eu não olhava [...] e criticava porque pra mim era supernormal ter um armário assim. [...] A gente sempre teve tudo, uma família de classe média [...]. Fizemos inglês, fizemos francês, moramos fora, fizemos balé. [...] Mas era uma vida controlada.

Nesse aspecto, a criação do site surgiu de uma convergência entre a finitude do espaço disponível, uma carreira construída no segmento digital, com práticas já mantidas no mundo offline e pré-negócio próprio:

A Maria comerciante fazia tudo pra vender. Odiava dar satisfação do meu dinheiro. Então eu precisava levantar fundos. Em um dado momento, eu meio que estava morando junto com meu marido. E ele queria um espacinho ali naquele guarda-roupa. Eu já vendia minhas roupas no banheiro da empresa em que eu trabalhava. [...] Catava tudo [...] e falava: "vem comigo". Em um dia eu vendia muito mais do que eu ganhava de salário. Era o que eu tinha, [...] roupa normal. Isto posto: eu já sabia vender. Eu sempre trabalhei com internet, então pra pegar aquele comportamento de vender minhas coisas e abrir o site foi um já, mas eu já fazia aquilo offline. Não era uma rotina, mas eu fazia de vez em quando. Eu não tinha vergonha de fazer, entende?

Em meio às infinitas opções do comércio, Maria Clara pondera sobre a atuação concreta das peças desejadas e sua opção por uma plataforma generalista:

Às vezes, uma camisa bem cortada que custou 20 reais é linda, faz uma diferença no todo absurda. [...] Ao longo da minha criação, percebi a lindeza da construção de marca. [...] A pessoa vai comprar aquela bolsa que custa 30 mil reais [...]. Às vezes, a pessoa que vai comprar a bolsa de 3 reais vai ficar muito mais incrível [ver] a produção inteira. Então não é a marca, [...] é o savoir porter. ...Também é muito legal você ter uma coisa que é uma marca que construiu e é um objeto de desejo. E você quer ter aquela coisa. Mas eu não diria que as marcas sozinhas conseguem ter isso representado, entende?

Embora Maria Clara já tivesse um lastro em relação ao digital, a manutenção de uma empresa própria trouxe reflexões sobre a distribuição da população em classes e suas preferências e gostos. Para ela, a renda disponível para compras de lazer tem mais a ver com "onde tem sobra e onde tem pouca sobra" no orçamento, levando a diferentes camadas. Em particular, a alta elite seria designada como "a gargalhada":

Tem baixa renda, média renda e alta renda. E tem a gargalhada. Já ouviu falar dessa? Eu acho que é algo acima do bem e do mal. Essa gargalhada é tão absurda... porque até aqui, de alta renda, 
a pessoa trabalha. Aqui o contexto é outro, a referência estética é outra, então ela vai buscar por marcas que vão denotar aquele significado de sucesso, mas dentro aquele contexto que eu entendo como bonito. [...] Para grande parte da população do Brasil, que a maior parte da população do Brasil acessa quando vê Riachuelo, C\&A, o que a gente chama de grandes marcas, magazine, [...] para elas aquilo já é muito caro. [...] Comprar Farm é para uma parcela mínima da população.

\section{E a gargalhada?}

A gargalhada é marcas que a gente nem sabe que existe. [...] São uns negócios assim... feito pra eles.

Assim como a empresa trouxe novas reflexões sobre a relação da clientela com marcas e até mesmo um repensar do luxo, o desenvolvimento profissional de Maria Clara se associou a modificações pessoais.

Ao longo da vida, fui muito bem profissionalmente, muito rápido, e pra isso eu tive que esconder muita coisa de mim mesma, especialmente o feminino. [...] Nem tinha noção de que eu estava escondendo o meu feminino para poder estar no lugar em que eu estava. Me fiz invisível ou [...] ouvi "Maria, você é tipo um cara! Você é muito legal". [...] O site foi muito legal para eu ser mulher. Inclusive se me perguntassem "Maria, como é ser mulher no mercado de trabalho?", até determinado momento, eu ia falar "Ué? Mas é diferente?”. Nem tinha noção [do] tão diferente e do tão brutal que era. Depois de ser mãe é que eu tive muita clareza das dificuldades. Hoje eu tenho um espaço em que eu não me sinto acuada. Já estou no board da companhia, não preciso mimetizar nada para estar num lugar. [...] Posso estar mais magra, eu posso ser eu. [...] Posso ser feminina e tudo bem.

De forma análoga, a incursão em viagens internacionais trouxe um leque e uma reconsideração do papel do luxo para a clientela brasileira:

Nas primeiras viagens dá uma sensação de que o mundo vai acabar. "[...] Nunca mais vou ter acesso a um crème hidratante” [...] Você quer comprar aquilo, é a busca por marcas que no Brasil são grife, e lá [...] você compra por 1 dólar. [...] Fui percebendo que [...] você acaba comprando um monte de coisa só porque acha que aquilo é uma oportunidade de compra. Em várias situações, [a mala] voltou super cheia. Hoje em dia é raríssimo. A verdade é que tudo tem no Brasil.

As vivências pessoais trouxeram, assim, modificações de perspectiva importantes para compreender a abrangência das peças:

Mudar do Rio para São Paulo, ou seja, uma pequena distância, já mostra muita coisa. [...] São Paulo é muito grande e tem muita gente, de todos os lugares do país, assim, uma cidade muito grande precisa ser mais organizada. A necessidade [...] faz o ladrão. Se ela for sambarilove vai dar ruim.

Assim como Inès, Maria Clara não se considerava particularmente apegada ao mundo da moda em si: "uso sempre a mesma roupa"; mas sentiu alterações na construção de seu estilo ao longo do tempo: 
"mais por eu já me conhecer melhor do que por qualquer outra coisa. [...] Você vai cair na emoção do momento de uma loja bonita? Vai. Mas tende a errar menos”.

Para a carioca, as roupas e o segunda mão eram menos uma questão afetiva do que um desdobramento de negócio bastante intuitivo por conta da sua própria formação. Contudo, vivências de família moldaram fortemente sua concepção de cultura material, e, de certa forma, seu percurso transpõe parte das percepções brasileiras acerca de viagens e do teor inacessível de certas peças. Ao contrário da visão de base nativa, que dispõe de uma predileção pelos importados, Maria Clara concluiu, satisfeita, que "tem tudo no Brasil” e que o próprio modelo local de comércio de segunda mão tinha um potencial não explorado à época do lançamento de seu site.

\section{Stella: do museu à galeria}

Stella nasceu na Argélia, onde cursou faculdade em comunicação, e se instalou em Paris aos 20 anos. Ali, sentiu-se dividida entre vários chamados, entre vocação e exigências para atuar no que a atraía:

Não me via enveredando [...] nesse mundo só com um diploma de comunicação [...] de empresas. Uma boa formação [...] faria a diferença. Fui contratada por um grupo franco-libanês. A gente vendia exclusivamente para o Oriente Médio e a Rússia [...] Fiquei na rota Beirute-Dubai-Paris por dois anos. Era compradora de prêt-à-porter e de estilistas, de criação, de peças novas.

O caminho de Stella rumo à segunda mão veio de uma necessidade pessoal.

Ganhei muitos presentes. Tenho muitas, muitas roupas. Comecei a deixar em consignação [...] porque não dava mais conta de tudo o que eu tinha. [...] Achei o conceito magnífico, a ideia de dar uma segunda vida, uma segunda chance, me intrigava o paradeiro da roupa quando a gente deixa de usar, eu me indagava: "mas pra onde ela vai? A gente guarda tantos anos e depois ela termina onde? No lixo?”.

Para Stella, o mercado de segunda mão traria

a oportunidade desses artigos serem revendidos e de agradar a uma cliente [...] que ama a moda e que ama o luxo e que não tem como comprar direto, novo, na loja. Então ela pode achar esses itens aqui. Daí a seleção de peças básicas, clássicas, marcas de prêt-à-porter francesas ou internacionais. E de fato aqui tem desde peças bem básicas até grandes peças de luxo. Eu queria uma mescla [...] porque me coloco no lugar das clientes.

Para começar, Stella adquiriu peças em leilões. Mas sua visão vai além da etiqueta: "não são apenas as grandes marcas que me interessam [...]. O estilo me interessa, os belos materiais me interessam. As cores me interessam. E sobretudo me interessa agradar a todos”. Assim, procurou adaptar sua proposta a um mundo em mutação onde observa, satisfeita, uma adesão crescente a brechós com curadoria seleta, como o seu:

O consumo feminino mudou. Agora é quase moda garimpar peças e encontrar uma em um brechó, que não foi muito cara. Mas antes era 
tabu. Quem morava no $14^{\circ}$ ia no brechó do $6^{\circ}$, quem morava no $6^{\circ}$ ia no $14^{\circ}$ e a outra do $14^{\circ}$ ia no $20^{\circ}$. Ninguém queria ser vista comprando de segunda mão. [...] Mas hoje todo mundo quer fazer negócio. Hoje, as peças são tão caras que no brechó a gente acha com 50 , às vezes $70 \%$ de desconto em relação à loja. E então as mulheres ficam realizadas ao encontrar ótima qualidade, lindos materiais, estilo por um preço razoável. Não querem mais dar tanto dinheiro, a não ser que sejam peças realmente excepcionais. [...] Já compram com a ideia de revender. [...] E isso permite reaver o dinheiro, é um investimento. Antigamente, a gente comprava pra ter. [...] A bolsa Hermès era pra vida toda, o lenço de seda era pra vida toda. Agora todo mundo entendeu: tem que girar. E é isso que me agrada, na verdade. [...] Não tem mais a mulher extremamente rica que pode... Não! Todo mundo compra, todo mundo vende.

Por outro lado, a atuação no brechó é muito próxima das clientes e também surge como oportunidade de desenvolver vínculos, inclusive com o styling das interessadas; por isso, embora tenha começado online, Stella prefere manter o seu ponto físico:

Quando comecei, trabalhei online 2 anos e até que vendia bastante. Mas a troca humana me fez muita falta. De ver a felicidade, o sorriso da cliente. ...E eu também ficava privada do meu trabalho de estilista, de personal. Preciso vestir, aconselhar e, caso não fique bom, vou dizer com sinceridade que não tá bom e sugerir outra peça. Fiquei bem infeliz trabalhando nesses dois anos online... O trabalho online me trazia dinheiro. Mas a loja física me traz experiências.

Mais uma vez, o Marais é tido como ponto-chave para instalação de uma loja seleta. Stella se percebe como pertencente a uma comunidade e escolheu a localização após estudos criteriosos:

A concorrência atrai. [...] A gente quer ter escolha e ter várias lojas mais ou menos na mesma pegada. Eu fiz uma pesquisa de mercado e uma de bairro antes de me instalar. Afinal, quando a gente monta um negócio assim, não é pra fechar em dois, três meses, é porque realmente me move. É o que gosto de fazer [...] E tem muitos turistas.

Todos os elementos da loja são pensados em relação às clientes potenciais e na relação com peças. Assim, Stella pretende comunicar suas intenções e a dinâmica de seu comércio desde a vitrine: "Vitrines frescas, coloridas, dão vontade [...]. Não monto vitrines de museu. Monto vitrines para dar ideias para as clientes [...]. Meu propósito é vestir”. De fato, as seleções são contemporâneas, embora Stella reconheça o papel do vintage na composição de estilos variados:

O vintage é muito importante. [...] A gente guarda preciosamente essas peças vintage, que atravessaram o tempo, por causa da história por trás, por causa da ideia por trás, mas não são as peças mais usadas hoje. As peças vintage a gente deixa pra um desfile. [...] O próprio vintage é um estado de espírito. Viver vintage é se adaptar a uma época, amar essa época e mesmo adaptar o seu estilo de vestimenta a essa época, mas procurando peças contemporâneas.

A grande motivação de Stella passa, portanto, pela construção minuciosa de laços, refletida em uma curadoria detalhista das peças 
disponíveis. Sua postura percebe o brechó quase como uma galeria de arte de elementos únicos, procurando se distanciar da concepção de "peças museu", válidas pela sua conservação, mas sem interesse real para um mundo em que "tudo gira" e as peças já não são adquiridas como patrimônio imobilizado.

\section{UM EMPREENDIMENTO SUSTENTÁVEL?}

Segundo a WWF-Brasil, o desenvolvimento sustentável é aquele "capaz de suprir as necessidades da geração atual, garantindo a capacidade de atender às necessidades das futuras gerações”' . Como indica a Figura 3, ao longo do tempo, a responsabilização em relação ao consumo de recursos, que de início era mais associada aos indivíduos, foi também atribuída às corporações. Hoje, inclusive, alguns modelos de avaliação de valor de empresas vão além da transformação de matéria-prima, e incluem os chamados pilares ESG (Environment - Sustainability - Governance, ou Ambiente, Sustentabilidade e Governança) no processo.

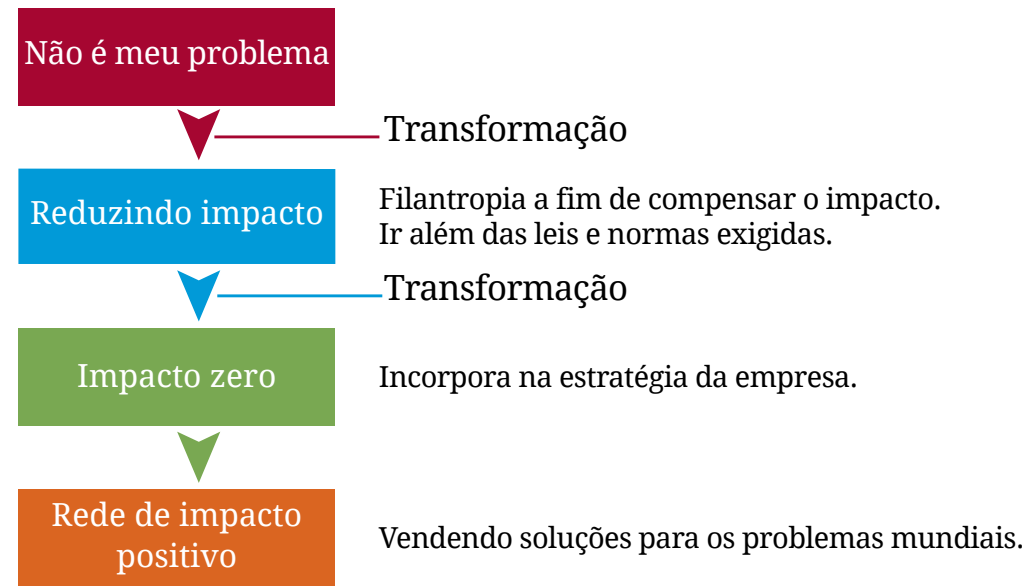

Figura 3. Evolução histórica da sustentabilidade e da responsabilidade social corporativa. Fonte: WWF-Brasil.

Essas propostas não se consolidaram nos últimos anos por acaso. Diante do inegável crescimento das mudanças climáticas, diferentes setores da economia são confrontados com a questão do fim dos recursos até aqui tratados como se fossem infinitos. Além disso, a proposta de fast fashion tem sido associada a vários tipos de escândalo trabalhista, utilizando-se de condições de trabalho precárias e com baixíssima remuneração. Tais acontecimentos levaram a uma revisão da economia da moda, sugerindo que produzisse com um foco maior na criatividade do que no volume massivo (CIETTA, 2017).

Onde entram as peças de segunda mão? Certamente têm mobilizado volumes expressivos, inclusive durante a pandemia da covid-19. O relatório de revendas da consultoria ThredUp (2021) estima que o mercado de revenda de peças aumentou de 9 para 15 bilhões de dólares entre 2020 e 2021, e oferece projeções de crescimento otimistas até 2025 (Gráfico 2).

4. Disponível em: https://bit.ly/3ejubi8. Acesso em: 22 dez. 2021. 


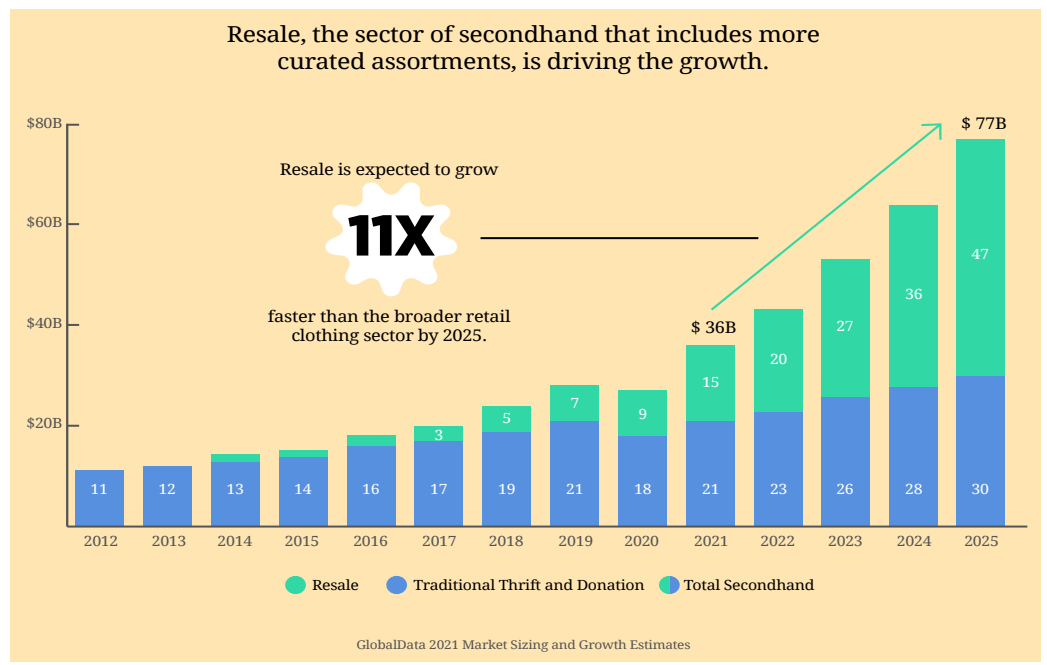

Gráfico 2. Crescimento do mercado internacional de segunda mão entre 2012 e 2021, com projeções até 2025.

Fonte: ThredUp (2021, p. 4).

Este mercado bilionário tem implementado novo vocabulário junto a suas peças e questões ambientais. $\mathrm{O}$ upcycling, por exemplo, é apresentado como um processo de reaproveitamento das roupas - por exemplo, converter uma calça jeans em uma bolsa customizada. $O$ discurso de Inès, em particular, se identifica com essa leitura ao defender uma visão direta de redução da emissão de carbono através do bom cuidado com as peças. Nesse sentido, a segunda chance a que se refere dialoga com a noção de economia circular (KOSZEWSKA, 2018), ou seja, a transformação de uma cadeia produtiva linear em uma cíclica, pautada em "pegar, fazer, usar, recuperar” (Figura 4) (BATISTA; GONG; PEREIRA; JIA; BITTAR, 2019, p. 7248).

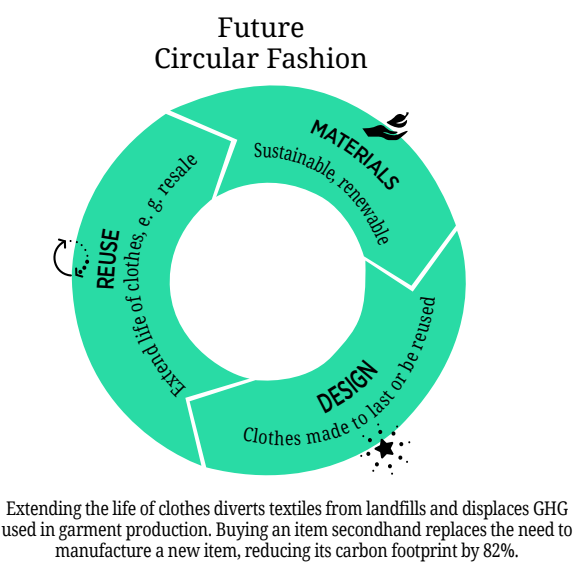

Figura 4. A proposta de moda circular.

Fonte: Thread Up (2021, p. 34).

Nesse aspecto, o brechó não é mais tido como reduto do descarte, das peças com percurso interrompido e uma sede meio embaraçosa, onde pessoas se sentiam envergonhadas em buscar artigos. Passa a se vincular com uma ideia do "vintage" como gerador de valor, inclusive financeiro.

Essa proposta modifica a noção de "novo", fundamental na cadeia produtiva linear. Até então, a peça nova era tida como virginal, 
à espera de quem a utilizasse, e acompanhasse fielmente até seu descarte, indo de par com Douglas (2012, p. 7), quando afirma que “[...] certos valores morais são protegidos e certas regras sociais definidas por crenças em contágios perigosos”. Nesse sentido, a roupa nova iria além de uma distinção social por conta do preço; a roupa usada, com contato corporal, profana a noção de "indivíduo" ao admitir que pessoas possam caber (e quase conviver, assincronamente) num mesmo receptáculo.

Se a sustentabilidade passaria por uma redução do gasto de recursos naturais, então as peças de segunda mão têm um imenso trunfo: já estão prontas em um cenário de matérias-primas cada vez mais escassas e custosas. Consumi-las impactaria diretamente nas emissões de carbono e, então, quem teria uma segunda chance seria o próprio planeta.

Mas é possível identificar outros pontos importantes na visão do "brechó sustentável". A noção de "giro", presente na fala de Stella, sublinha uma engrenagem estética e pessoal, em que se assume que cada peça durará mais do que a identificação da proprietária com sua proposta, e que, quando não atender à primeira pessoa, pode ter novas aventuras com novas donas. Nesse ponto, a "roupa nova" é a novidade, não aquela nunca usada. Mas sobretudo, esta visão converge para uma noção de "estilo único" bastante individualista - em que cada cliente procuraria opções fora da massificação para expressar sua identidade (FARRA, 2020). Nessa perspectiva, quem merece uma segunda chance é o próprio ideal de expressão pessoal através do ato de se vestir, gesto entendido como 0 auge da modernidade individualista (LIPOVETSKY, 2004) .

Um terceiro ponto relevante é quando são as pessoas, e não as roupas, que circulam. No Brasil, a compra no exterior é entendida como símbolo de acesso a mundos e referências que não estão presentes no país de origem (SOARES, 2017). Nesse sentido, a inserção dos brechós pode ser positivamente explicada como um "atalho" que reduz assimetrias socioeconômicas (ASSUNÇÃO, 2021).

Apesar dessas explicações positivas, é preciso sublinhar o fator discurso. As entrevistadas podem ser entendidas como porta-vozes de um mercado crescente e complexo. Mas a compra de peças usadas não é um ato de redenção per se. Precisamos nos perguntar se esses mesmos brechós, que hoje podem ser iniciativas milionárias (NO ENJOEI..., 2021), respondem aos pilares ESG; se propõem um modelo de negócio que vai além do repasse da própria peça; se a segunda mão competirá apenas com o fast fashion ou se chegará a discutir pontos maiores, como a própria produção de tecidos, e não das peças.

\section{CONSIDERAÇÕES FINAIS}

Os brechós deixaram de ser uma saída "inferior" numa hierarquia de cultura material que, por um longo período, privilegiou o novo. Os relatos das entrevistadas possibilitaram perceber a construção própria da "segunda chance" embutida ao relançar um bem, em particular roupas e acessórios, no mercado. Para Inès, a segunda chance passa sobretudo por reduzir a sobrecarga planetária; para Stella, unir uma nova dona a um bem com o qual se conecte pode trazer alegrias e novas propostas

5. É sintomática a fala da empresária do vintage Sofia Bernardin, em entrevista para o Financial Times, em que seleciona "apenas as peças que entende como representativas da modernidade” (FURY, 2020). 
de estilo, numa constante reconfiguração visual de si própria; e Maria Clara retrabalhou percepções e práticas, tanto suas como da clientela, reduzindo o grau de resistência local às peças de segunda mão como alternativas legítimas.

Esses projetos foram longamente produzidos e aplicados com uma bagagem prévia de trabalho - nesse sentido, aparecem como empreendimentos elaborados, que mesclam relações com pessoas, leituras geopolíticas e adaptações a novos contextos de comércio e de cultura material. Nem sempre os aspectos digitais foram plenamente dissociados dos pontos físicos, e nem sempre a segunda chance, ou seja, a visão sobre "sustentabilidade" (VEIGA, 2010) diz respeito unicamente à visão do impacto produtivo, embora esteja presente. Entram em jogo, ainda, as percepções das pessoas, novos leques de referências e as afinidades particulares de cada testemunho sobre como lidar com um mundo dos bens em que a posse de longo prazo já não é praxe.

\section{REFERÊNCIAS}

ASSUNCCÃO, Luxas. O mercado de segunda mão pode salvar a moda? FFW, [s. I.], 10 set. 2021. Disponível em: https://bit.ly/3H31uT6. Acesso em: 20 out. 2020.

BARTHES, Roland. Système de la mode. Paris: Points, 2014

BATISTA, Luciano; GONG, Yu; PEREIRA, Susana; JIA, Fu; BITTAR, Alexandre. Circular supply chains in emerging economies: a comparative study of packaging recovery ecosystems in China and Brazil. International Journal of Production Research, London, v. 57, n. 23, p. $7248-7268,2019$

BORGES, Silvia; DUBEUX, Veranise. Comercialização e consumo de vestuário de segunda mão na cidade do Rio de Janeiro. In: ENCONTRO NACIONAL DE ESTUDOS DO CONSUMO, 6., 2012, Rio de Janeiro. Anais [...]. Rio de Janeiro: Enec, 2012. p. 1-15.

CIETTA, Enrico. A economia da moda. São Paulo: Estação Letras e Cores, 2017.

DOUGLAS, Mary. Pureza e perigo: ensaio sobre as noções de poluição e tabu. São Paulo: Perspectiva, 2012.

ELLEN MACARTHUR FOUNDATION. A new textiles economy: redesigning fashion's future. [S. I.]: Ellen MacArthur Foundation, 2017. Disponível em: https://bit.ly/3JbUkOJ. Acesso em: 7 dez. 2020

FARRA, Emily. 2020 was a big year of old clothes: how vintage, secondhand, and upcycling took off. Vogue, [S. I.], 21 nov. 2021. Disponível em: https://bit.ly/3eeRLg4. Acesso em: 20 out. 2021.

FERREIRA FREITAS, Ricardo. Centres commerciaux: îles urbaines de la post-modernité Paris: L'Harmattan, 1996.

FURY, Alexander. Va-va-vintage. The rise and rise of resale. Financial Times, London, 21 out. 2020. Disponível em: https://on.ft.com/3yPkLo0. Acesso em: 20 out. 2021.

GRUMBACH, Didier. Histoire de la mode. Paris: Éditions du Regard, 1993

GWOZDZ, Wenke; STEENSEN NIELSEN, Kristian; MÜLLER, Tina. An environmental perspective on clothing consumption: consumer segments and their behavioral patterns. Sustainability, Basel, v. 9, n. 7, p. 762, 2017.

HANSEN, Karen Tranberg. Salaula: the world of secondhand clothing and Zambia. Chicago: University of Chicago Press, 2000.

HAZAN, Eric. A invenção de Paris: a cada passo uma descoberta. São Paulo: Estação Liberdade, 2017.

KOPYTOFF, Igor. The cultural biography of things: commoditization as process. In: APPADURAI, Arjun (org.). The social life of things: commodities in cultural perspective. Cambridge: Cambridge University Press, 1988. p. 64-92. 
uma etnografia. 2010. Dissertação (Mestrado) - Pontíficia Universidade Católica do Rio Grande do Sul, Porto Alegre, 2010.

KOSZEWSKA, Małgorzata. Circular economy: challenges for the textile and clothing industry. Autex Research Journal, Lódz, v. 18, n. 4, p. 337-347, 2018.

LIPOVETSKY, Gilles. L'empire de l'éphémère : mode et modernité dans les sociétés modernes. Paris: Folio Essais, 2004.

MACHADO DE ASSIS, Joaquim Maria. Ideias do Canário. In: MACHADO DE ASSIS, Joaquim Maria. Páginas recolhidas. São Paulo: Globo, 1997. p. 66-74.

NO ENJOEI, volume de vendas cresce 82\% em um ano e chega a R\$205 milhões. Seu Dinheiro, São Paulo, 12 jul. 2021. Disponível em: https://bit.ly/3JcmYP5. Acesso em: 20 out. 2020.

ROCHE, Daniel. La culture des apparences: une histoire du vêtement (XVIle-XVIIle siècle). Paris: Fayard, 1989.

SILVA, Gabriela Jobim da. Design 3D em Tecelagem Jacquard com ferramenta para a concepção de novos produtos - aplicação em acessórios de moda. 2005.

Dissertação (Mestrado em Design e Marketing) - Universidade do Minho, Braga, 2005.

SOARES, Cecilia Elisabeth Barbosa. Sedas tropicais: comércio de luxo e desenvolvimento urbano no Rio de Janeiro. 2017. Tese (Doutorado em Sociologia) - Universidade do Estado do Rio de Janeiro, Rio de Janeiro, 2017.

THREDUP. 2021 Resale Report. Oakland: ThredUp, 2021. Disponível em: https://bit.ly/3efsUJ9. Acesso em: 20 out. 2021.

VEIGA, José Eli da. Indicadores de sustentabilidade. Estudos Avançados, São Paulo, v. 24, n. 68, p. 39-52, 2010. 